\title{
Introduction to IIPF 2020 special issue in ITAX: reflections on the interactions between environmental economics and public finance
}

\author{
Mireille Chiroleu-Assouline ${ }^{1}\left[\right.$ Marco Runkel $^{2}$
}

Accepted: 19 August 2021 / Published online: 19 October 2021

(C) The Author(s), under exclusive licence to Springer Science+Business Media, LLC, part of Springer Nature 2021

This special issue of International Tax and Public Finance contains selected papers presented at the 76th Annual Congress of the International Institute of Public Finance (IIPF), which was hosted by the University of Iceland on August 19-21, 2020. Due to the Covid-19 pandemic, for the first time this congress was held in an online format. The number of presentations at the congress was slightly lower than at past physical IIPF congresses despite an initially higher number of submissions (588). But with 290 papers presented in contributed sessions covering all topics within public economics, it still remarkably high, given the circumstances during the pandemic and the fact that it was the first online congress of the IIPF.

The theme of the conference was "Public Finance, Natural Resources and Climate Change." It had been chosen in 2019, long before the Covid-19 crisis erupted, and reflected the need to move forward on policies to achieve the long-term climate goals outlined in the 2016 Paris Agreement. The health crisis, however, did not undermine the need to address the climate crisis. On the contrary, the Covid-19 crisis-similar to global warming - shows the dramatic vulnerability of mankind to changes in its natural environment. Climate and health crises, together with their possible interactions, therefore represent a 'twin crisis' that belongs to the largest challenges of the twenty-first century. For this reason, the scientific committee of the congress decided to adhere to the overall conference theme, where possible and suitable complemented by some aspects of the Covid-19 pandemic.

Mireille Chiroleu-Assouline

Mireille.Chiroleu-Assouline@univ-paris1.fr

http://www.parisschoolofeconomics.eu/en/chiroleu-assouline-mireille/

Marco Runkel

marco.runkel@tu-berlin.de

http://www.finance.tu-berlin.de

1 Paris School of Economics \& University Paris 1 Panthéon-Sorbonne, 48, boulevard Jourdan, 75014 Paris, France

2 Technische Universität Berlin, Straße des 17. Juni 135, 10623 Berlin, Germany 
The climate issue has traditionally been the domain of environmental and natural resource economics, but the treatment of environmental quality or the habitability of the planet as global public goods, as well as that of pollution or GHG emissions as externalities, and-last but not least - the potential correction by taxes, subsidies, emission trading systems or other kinds of regulation makes public economics the parent discipline to refer to. In previous decades, both disciplines-environmental and resource economics, on the one hand, and public economics, on the other hand-have taken their own development with their own scientific associations, conferences and field journals. What does a congress of the IIPF with the climate issue as the main conference theme tell us about the way the relationship between environmental economics and public economics is evolving? Before introducing the papers published in this special issue, we will address this question by briefly discussing the keynote lectures as well as some (very) selective papers presented in the contributed sessions of the congress and not published in the special issue.

\section{Keynotes and selective presentations}

Four inspiring keynote speakers have been invited to talk on the central conference theme: Ottmar Edenhofer (Potsdam Institute for Climate Impact Research and Technische Universität Berlin) on "Pigou in the Post-Corona Era", Karen Palmer (Resources for the Future) on "Flexible Electricity Demand and Decarbonization: Policy, Prices and Automation", Rick van der Ploeg (University of Oxford) on "Climate Policy, Natural Resources and Public Finance Post Covid-19" and Anna Alberini (University of Maryland) on "All Car Taxes are Not Created Equal: Evidence from Germany". The keynote lectures allowed both to deepen the relationship between the fields of public finance and climate policy and to provide conference participants with specific insights into aspects that are often overlooked by non-specialists. ${ }^{1}$

Ottmar Edenhofer went back to the origins by painting a comprehensive picture of the obstacles to the implementation of Pigouvian carbon taxation, but also of its successes, and his talk provided a number of stimulating avenues of research. He based his arguments on both a sound scientific basis and excellent knowledge of the scientific literature as well as comprehensive practical experiences in policy consulting, a combination that turned out to be highly fruitful. Among the implementation difficulties he mentioned was the problem of assessing the social cost of carbon, and this was precisely the issue addressed by Rick van der Ploeg. He particularly insisted on the presence of multiple sources of uncertainties and on the importance of the choice of the discount rate, a subject that gains a lot of attention in environmental and resources economics not only since the release of the Stern-Review on

\footnotetext{
1 All keynote lectures are available in video on the permanent conference website: https://www.iipf.org/ cng20.htm.
} 
the economics of climate change ${ }^{2}$ and, at the same time, is familiar to researchers in public finance when the policy envisaged has long-term objectives. But perhaps one of the most original points for the usual IIPF conference audience was his proposed incorporation of a model of temperature variation to account for the reciprocal interactions between climate and economic activity, in line with the work of William Nordhaus, who was awarded the Bank of Sweden prize in 2018.

The other two keynote lectures dealt with the power generation and passenger car sectors, which were among the first to be regulated in the EU to reduce their GHG emissions, but for which much remains to be done and effective regulation requires a thorough understanding of the underlying mechanisms. Starting from the recognition that long-term climate goals can only be met if major efforts are made to decarbonize electricity generation and electrify other energy uses, Karen Palmer focused on demonstrating the usefulness of market-specific instruments: since the integration of renewables into the energy mix poses supply-demand matching challenges, automation and innovative tariff design can help facilitate efficient demand shifting, with direct and indirect climate benefits. Finally, Anna Alberini presented a study, using German data, of the effects of an annual registration tax that increases with a vehicle's $\mathrm{CO}_{2}$ emission rate. ${ }^{3}$ She showed that this type of tax is effective in shifting new cars to lower-emission models, but that these effects seem to disappear over time. Finally, drivers seem to integrate the information they receive on the future evolution of the cost of using their vehicle in different ways, depending on the type of tax and the way it is calculated. Both the talk of Karen Palmer and the talk of Anna Alberini show the importance of carefully analyzing the usefulness of basic public finance instruments in the design of a suitable climate policy, that is central in environmental and resource economics.

Beyond these four plenary lectures, the IIPF 76th Annual congress was the occasion for a notable opening to works in environmental economics. Among all accepted papers, there were 42 papers classified with the topic 'Environment', divided into subgroups 'Climate change policy', 'Natural resources', 'Environmental tax reforms', 'Mobility and congestion', 'Public investment and public procurement', 'Energy taxation' and 'Green bonds'. From these papers, we formed three sessions with the general title 'Environmental Economics', three sessions named 'Environmental Regulation' and one specific session on 'Distributional Effects of Environmental Policies'. In addition, there were single papers on environmental issues included in broader sessions on, for example, 'Local Public Finance' and 'Growth and Fiscal Policies'. Among the many exciting papers presented at this conference, we would like to mention a few that may be representative of new research avenues for the future, some of which have since been published in other journals.

The first strand of papers which we would like to highlight discusses environmental policy in a framework where not all market participants are solely

\footnotetext{
2 Stern, N. (2006). Stern Review on the Economics of Climate Change. UK Government Economic Service, London. www.sternreview.org.uk.

${ }^{3}$ Published as Alberini, A., \& Horvath, M. (2021). All car taxes are not created equal: Evidence from Germany. Energy Economics, 100, Article 105329.
} 
self-interested, but also have some kind of social or green preferences. These papers within the field of environmental and resource economics therefore emphasize the importance of behavioral aspects in the design of environmental and climate policy, aspects that have gained general interest in the field of public economics over the last decades ('behavioral public economics').

The paper "Can Subsidies Rather Than Pollution Taxes Break The Trade-Off Between Economic Output And Environmental Protection?" by Thomas Renström, Luca Spataro and Laura Marsiliani ${ }^{4}$ revisits the debate on the choice between taxing polluting emissions and subsidizing the abatement activities of perfectly competitive firms in which investors can be socially responsible. This social responsibility objective of investors is represented by a warm-glow mechanism à la Andreoni, so that they feel partly responsible for the pollution content of their portfolio and, at equilibrium, demand a "pollution premium" in order to hold "dirty assets". Firms are incentivized to engage in cleanup activities by investors' portfolio choices, as higher pollution also implies a higher cost of capital in the capital markets. Using a continuous time model, the authors compare the effectiveness of the two types of fiscal policy in improving environmental quality and the conditions under which they can also improve the economic performance. They show that while both can be successful in reducing pollution, their effects on the performance of the economy can be quite different: while the pollution tax always reduces per capita consumption and the capital installed in the economy, the subsidy can increase both. Indeed, in this model the pollution tax corresponds to a tax on profits, which reduces the marginal productivity of capital and induces firms to reduce capital investment and thus reduce pollution flows and the pollution premium. In contrast, the pollution abatement subsidy reduces firms' production costs, so that it induces an increase in firm size, and thus in installed capital, output, and consumption per capita, but also in the resources that firms devote to pollution abatement, thereby reducing pollution as well as the pollution premium.

The second paper with behavioral market participants was presented by Laura Birg and Jan S. Voßwinkel entitled "Green Consumers, Emission Taxes, and Firm Relocation". 5 This paper lies at the intersection of two strands of literature, introducing the risk of firms relocating abroad into the analysis of the effect of environmental policy in the presence of green consumers in a vertical duopoly with two types of firms, a 'green' firm with high environmental quality and a 'brown' firm with low environmental quality. The authors shed new light on the pollution haven hypothesis by emphasizing the impact of relocation on firms' environmental quality choices. They show that the combination of the environmental tax with the private incentives provided by consumers' willingness to pay for green products produces complex effects, with offshoring decisions resulting from the emissions tax affecting

\footnotetext{
${ }^{4}$ Published as Renström, T. I., Spataro, L., \& Marsiliani, L. (2021). Can subsidies rather than pollution taxes break the trade-off between economic output and environmental protection? Energy Economics, 95, Article 105084.

5 Published as Birg, L., \& Voßwinkel, J. S. (2021). Emission taxes, firm relocation, and product differentiation. European Journal of Law and Economics, 51(2), 297-345.
} 
the quality levels of both firms. If the green firm does not relocate, both the green firm and the brown firm provide better environmental quality products. At the same time, if the green firm does not outsource but the brown firm does, the difference in quality is the highest, implying that competition between the firms is the lowest. The welfare-maximizing environmental policy then changes with firm offshoring.

The second strand of papers is on the trade-off between environmental policy, on the one hand, and economic growth and employment, on the other. We would like to emphasize these environmental economics papers, because they are related to the question of equity and inequality, which has become one of the major topics in public economics over the last decades (with a large number of separate sessions at the IIPF 2020 congress on topics like, e.g., 'Distributional Effects of Taxation', 'Inequality' and 'Optimal Tax-Transfer Policy').

One relevant paper in this strand is "Environmental Policies in a Stagnant Economy" presented by Masako Ikefuji and Yoshiyasu Ono. They consider a stagnant economy that faces involuntary unemployment due to a shortage of aggregate demand. ${ }^{6}$ Using a theoretical model, they examine the effects of environmental policies, such as an emissions tax or a public pollution control policy, on consumption, pollutant emissions and welfare. They find that, in such an economy, environmental regulation reduces pollution but more importantly creates new jobs, reduces inflation and stimulates consumption. A double dividend can thus be obtained thanks to the unused labor force until full employment is achieved.

In a similar spirit, Marc Hafstead and Roberton Williams presented a paper entitled "Distributional Effects of Environmental Policy across Workers: A GeneralEquilibrium Analysis" in which they use a computable general equilibrium model to study the sectoral decomposition and dynamics of the effects of environmental policy on workers' employment, wages and unemployment duration. They find that the significant negative impacts mainly affect workers initially employed in a few carbon-intensive industries. Finally, they show that pre-announcement and phase-in of policies can significantly reduce short-term negative employment impacts, both overall and for the most affected groups of workers.

As a third and final strand of papers, we would like to mention papers concerned with the political economy of environmental policy. As for all kinds of policies analyzed in public economics, political economy issues are key to the question of whether suitable climate policies can be implemented in practice. Many of the arguments in Ottmar Edenhofer's keynote lecture circled around this question and also the paper by Pauli Lappi, published in this special issue and refereed to below, is on the political economy of environmental policy.

In addition, we would like to showcase the paper "Climate Policy and Inequality in Two-Dimensional Political Competition," presented by Waldemar Marz. Interestingly, this paper is relevant for both the second and third strands of papers that we have highlighted here, since it refers to the inequality issue as well as to political competition in the presence of climate policy. More specifically, the author proposes

\footnotetext{
${ }^{6}$ Published as Ikefuji, M., \& Ono, Y. (2021). Environmental policies in a stagnant economy. Economic Modelling, 102, Article 105574.
} 
an innovative theoretical framework to analyze the reasons for the rejection of environmental policies in economies marked by income inequality. He models a twodimensional political competition on an environmental policy with distributional implications, the carbon tax and the redistributive policy through the proportional income tax at the same time. He shows that the greater the pre-tax income inequality or the more importance voters place on the issue of redistribution, the greater the polarization of carbon tax proposals across parties-even if the income tax is used to counteract rising income inequality. Remarkably, this result does not depend on the progressivity of the carbon tax revenue recycling mechanism.

Overall, this brief review of selected papers presented at the congress reveals some important and fruitful common points of interest between environmental economics and public economics. Nevertheless, some blind spots remain. For instance, in spite of the title of the conference, the subfield of natural resource economics was not represented by a substantial number of papers. The same is true for the various subfields dealing explicitly with the interactions between nature and economics (biodiversity conservation, sustainability issues, sustainability theory). This is both understandable and regrettable. It is understandable because the methods of analysis used in these fields are very specific, often based on formalization and a high degree of technicality, in which only researchers in the field invest, under the strong pressure of the increasing specialization of research in economics. But this is unfortunate because the investigation of these complicated relationships between the economy, natural resources, whether exhaustible or renewable, and nature may benefit public economics in a similar way as public economics has influenced-and in the future for sure continues to influence-the analysis of topics in environmental and resource economics. Despite the lack of corresponding papers presented at the IIPF 2020 congress, we hope that including topics from environmental and resource economics into the main theme of a public finance congress will nevertheless stimulate further research on the intersection of these two important research fields.

\section{Content of this special issue}

Two of the keynote speakers decided to write a paper based on their plenary talk and submit it to the special issue. These two contributions, which offer complementary and overarching views on carbon pricing, will undoubtedly become major references in the literature and we thank their authors again for submitting them to this special issue.

In his paper "Pigou in the 21st Century: A tribute on the occasion of the 100th anniversary of the publication of The Economics of Welfare," jointly written with Max Franks and Matthias Kalkuhl, Ottmar Edenhofer critically reviews the widespread view that Pigouvian pricing is well-founded from a theoretical point of view, but connected with a lot of implementation problems and therefore infeasible in practice. The authors identify a number of theoretical and political challenges, but also point to recent success stories in implementing the Pigouvian principle in practice. Finally, the authors briefly identify some possible ways to go for future research on the Pigouvian approach. Overall, the paper gives a very informative 
and differentiated view on Pigouvian pricing which is stimulating for both further research and political discussions on this central topic in climate policy.

The application of the Pigouvian principle relies in fact on the evaluation of the social cost of carbon, defined as the present value of the damage caused to the society by the emission of a ton of carbon today. Based on his keynote lecture, Rick van der Ploeg discusses in his paper "Carbon pricing under uncertainty" the sensitivity of this social cost of carbon to different types of uncertainty-climatic and economic - and to the risk of economic disasters and of climatic tipping points. He argues that the effect of these uncertainties, combined with the choices to be made about the discount rate for future damages, is to significantly widen the confidence interval of the social cost of carbon, which justifies the more pragmatic approach adopted by policy makers at the Paris agreement in 2016. The choice of a temperature cap implies a cap on cumulative global emissions, which the paper shows is sensitive to the uncertainty of temperature sensitivity and risk tolerance, requiring the price of carbon to grow over time at a rate different from the rate of interest.

Next to these two papers based on the IIPF 2020 keynote lectures, the special issue contains five papers that were presented in contributed sessions of the congress and that deal with a variety of topics from public economics.

Closely related to the main theme of the congress is the paper "Lobbying for size and slice of the quota" by Pauli Lappi. The author presents a two-stage common agency framework in which several principals (countries or firms) give contribution payments to a single agent (regulator) that sets the overall size and distribution of an emission quota. The basic insight is that lobbying leads to an inefficiently high number of permits. However, if the environmental damage taken into account by the agent just reflects the sum of damages of the principals, the emission quota is efficient, even though each principal takes into account only his own damage. The reason is that the principals' contributions sum up and thereby give the agent the incentive to choose the quota as if it maximizes social welfare. Overall, the important contribution of the paper is to show that the efficiency implications of lobbying depend on the aggregated damages taken into account by principals and agents.

The following two papers deal with the consequences of certain international tax rules on profit shifting incentives, thus contributing to a topic that was very prominent at the conference.

Entitled "Designing international tax reform: lessons from TCJA", the paper by Mindy Herzfeld analyzes the motivations for and effects of the tax law changes enacted in the United States by the Tax Cuts \& Jobs Act (TCJA) in terms of their impact on cross-border trade and investment by comparing them to the goals of international tax reform that were widely supported prior to the law's enactment. She finds that in fact the changes in the law seem to have been far from achieving the desired results. In particular, the new system has neither eliminated incentives for profit shifting nor leveled the playing field between US and foreign multinationals. This failure appears to be due in large part to an inadequate appreciation of the consequences of the interactions between the complex new rules and existing law.

The paper "Tariff Elimination versus Tax Avoidance: Free Trade Agreements and Transfer Pricing" by Hiroshi Mukunoki and Hirofumi Okoshi uses a monopoly model of a multinational enterprise in order to identify the so-called Rules of Origin (ROO) 
within a Free Trade Agreement (FTA) as a means to reduce profit shifting. Under the ROO, exporters have to identify the origin of exports to be eligible for a preferential tariff rate in the FTA. Under the value-added version of this rule, the difference between the exported goods' output and input prices, relative to the output price, has to be higher than a certain threshold value. If the multinational manufactures the input good in a tax haven outside the FTA, the ROO gives the multinationals an incentive to reduce the transfer prices of the input good and, thus, profit shifting to the tax haven. If the incentive is strong enough, it is even possible that the direction of profit shifting is reversed. Because of higher tax revenues inside FTA countries, the ROO may render the FTA welfare-increasing.

The next two articles in this special issue are devoted to the impacts of the value added tax design on growth.

This is explicitly the case for the paper entitled "The Value Added Tax and Growth: Design Matters" by Santiago Acosta-Ormaechea and Atsuyoshi Morozumi. It examines, for OECD countries over the 1970-2018 period, the effects on long-term growth of a value-added tax (VAT) increase that does not affect total tax revenues because it is offset by a decrease in income tax, depending on how the VAT is increased. In most of these countries, there is a system of exemptions and reduced rates on various grounds that lowers the amount of VAT actually levied. The results of this paper suggest that a broadening of the VAT base through fewer exemptions and a more uniform rate structure with fewer reduced rates is more growth-enhancing than simply raising the standard rate.

In their paper "VAT threshold and small business behavior: evidence from Thai tax returns," Athiphat Muthitacharoen, Wonma Wanichthaworn and Trongwut Burong show that the growth of small firms in a country like Thailand, characterized by high VAT informality (defined as the presence of non-VAT registered firms), is constrained by the existence of a size-dependent VAT registration threshold. In particular, their results clearly reveal a bunching response of firms to the threshold and that non-VATregistered firms have a significantly lower growth rate than a propensity score-matched group of firms that voluntarily registered. These effects are stronger for firms near the threshold, which is likely due to misreporting.

In particular, the papers on profit shifting and the VAT published in this special issue show that the range of topics discussed at the IIPF congress 2020 was much broader and not only confined to public finance issues of environmental and resource policies. Similar to previous IIPF conferences, while the 2020 congress addressed the main conference theme in keynote lectures and a substantial number of contributed sessions, it was also open to papers on all topics discussed in public economics. In order to reflect the resulting variety of topics presented in contributed sessions, the editors of International Tax and Public Finance agreed on contributing to the special issue. Their paper offers a view on some general developments in public economics revealed by the congress and closes this special issue. 


\section{Prizes and awards}

The 2020 congress also featured a number of prizes and awards. The 2020 Peggy and Richard Musgrave Prize for the best paper contributed by authors under the age of 40 was awarded to Jósef Sigurdsson (Bocconi University, Italy; now Norwegian School of Economics in Bergen, Norway) for his paper "Labor Supply Responses and Adjustment Frictions: A Tax-Free Year in Iceland". In addition, the IIPF Young Economists Awards were given to the following researchers: Ashley Cooper Craig (University of Michigan, USA) for his paper "Optimal Income Taxation with Spillovers from Employer Learning", Andreas Gerster (University of Mannheim, Germany) and Michael Kramm (Technical University of Dortmund, Germany) for their paper "Correct Me if You Can-Optimal Non-Linear Taxation of Internalities" and Arezou Zaresani (University of Melbourne, Australia) for her paper "Adjustment Cost and Incentives to Work: Evidence from a Disability Insurance Program." The 2020 ITAX PhD Student Award was presented to Thiago Scot (UC Berkeley, USA) for the paper "Corporate Taxation and Evasion Responses: Evidence from a Minimum Tax in Honduras" which was co-authored with Felipe Lobel (UC Berkeley, USA) and Pedro Zúniga (Servicio de Administración de Rentas, Honduras). More than 80 papers applied for the IIPF awards, and more than 60 for the ITAX award.

\section{Conclusion and acknowledgments}

Despite the unfavorable conditions due to the pandemic, the 2020 IIPF Congress was a great success and we are grateful to all the authors submitting their papers to the congress and being prepared to present the papers in the online format. The same thanks go to the keynote speakers and all the discussants of papers in the contributed sessions. We also thank the many authors who decided to submit their papers to the IIPF special issue. The congress itself and, therefore, also the publication of articles in this special issue would not have been possible without the help of the members of the Scientific Committee. We are grateful for their great effort and advice in reviewing hundreds of papers submitted to the congress. We are also thankful for the assistance we received from the editors and staff of International Tax and Public Finance during the publication process of the special issue. Last but not least, we would like to express our deep gratitude to Barbara Hebele of the IIPF and to the local organizers in Reykjavik chaired by Pórólfur Geir Matthíasson (University of Iceland, Iceland). Working together with Barbara as well as with Pórólfur and his friendly team was always fun, and we think that together we managed to make this first online IIPF congress an important experience and a memorable event!

Publisher's Note Springer Nature remains neutral with regard to jurisdictional claims in published maps and institutional affiliations. 